\title{
Complete oxidation of hydroxymethylfurfural to furandicarboxylic acid by aryl-alcohol oxidase
}

\author{
Ana Serrano ${ }^{1}$, Eva Calviño², Juan Carro ${ }^{1}$, María I. Sánchez-Ruiz ${ }^{1}$ F. Javier Cañada² and Angel T. Martínez ${ }^{1 *}$ (D)
}

\begin{abstract}
Background: 5-Hydroxymethylfurfural (HMF) is a highly valuable platform chemical that can be obtained from plant biomass carbohydrates. HMF can be oxidized to 2,5-furandicarboxylic acid (FDCA), which is used as a renewable substitute for the petroleum-based terephthalic acid in polymer production.

Results: Aryl-alcohol oxidase (AAO) from the white-rot fungus Pleurotus eryngii is able to oxidize HMF and its derivative 2,5-diformylfuran (DFF) producing formylfurancarboxylic acid (FFCA) thanks to its activity on benzylic alcohols and hydrated aldehydes. Here, we report the ability of AAO to produce FDCA from FFCA, opening up the possibility of full oxidation of HMF by this model enzyme. During HMF reactions, an inhibitory effect of the $\mathrm{H}_{2} \mathrm{O}_{2}$ produced in the first two oxidation steps was found to be the cause of the lack of AAO activity on FFCA. In situ monitoring of the whole reaction by ${ }^{1} \mathrm{H}-\mathrm{NMR}$ confirmed the absence of any unstable dead-end products, undetected in the HPLC analyses, that could be responsible for the incomplete conversion. The deleterious effect of $\mathrm{H}_{2} \mathrm{O}_{2}$ was confirmed by successful HMF conversion into FDCA when the AAO reaction was carried out in the presence of catalase. On the other hand, $\mathrm{no} \mathrm{H}_{2} \mathrm{O}_{2}$ formation was detected during the slow FFCA conversion by AAO in the absence of catalase, in contrast to typical oxidase reaction with HMF and DFF, suggesting an alternative mechanism as reported in some reactions of related flavo-oxidases. Moreover, several active-site AAO variants that yield nearly complete conversion in shorter reaction times than the wild-type enzyme have been identified.
\end{abstract}

Conclusions: The use of catalase to remove $\mathrm{H}_{2} \mathrm{O}_{2}$ from the reaction mixture leads to $99 \%$ conversion of HMF into FDCA by AAO and several improved variants, although the mechanism of peroxide inhibition of the AAO action on the aldehyde group of FFCA is not fully understood.

Keywords: Biocatalysis, Aryl-alcohol oxidase, Mutated variants, 5-Hydroxymethylfurfural, 5-Formylfurancarboxylic acid, Inhibition, Hydrogen peroxide, Catalase, 2, 5-Furandicarboxylic acid, Polymer building blocks

\section{Background}

Interest in the production of new chemicals and materials from renewable resources has exponentially grown in the last years with biomass-derived compounds as a future alternative to fossil-based compounds. Among them, 2,5-furandicarboxylic acid (FDCA) has been reported by the US Department of Energy as one of the

\footnotetext{
*Correspondence: atmartinez@cib.csic.es

${ }^{1}$ Biotechnology for Lignocellulosic Biomass, Centro de Investigaciones

Biológicas, CSIC, Ramiro de Maeztu 9, 28040 Madrid, Spain

Full list of author information is available at the end of the article
}

top 12 value-added chemicals derived from biomass [1, 2]. Its importance mainly lies in the possibility of using FDCA as a renewable building block for the production of poly(ethylene 2,5-furandicarboxylate) (PEF) through polymerization with ethylene glycol. PEF is expected to substitute for conventional poly(ethylene-terephthalate) (PET) plastics due to its renewable origin and its better chemical and gas barrier properties [3, 4]. For these reasons, the production of FDCA from lignocellulose biomass has gained interest in the last years and different efforts were made to develop a biological methodology for FDCA synthesis, as an alternative to the chemical ones. 
FDCA production from lignocellulose biomass involves first the production of 5-hydroxymethylfurfural (HMF). This compound is obtained by dehydration of monosaccharides (generally fructose) that can originate from cellulose hydrolysis, followed by glucose isomerization [5-7]. Then, FDCA is obtained from HMF through three consecutive oxidation steps with two alternative intermediates, 2,5-diformylfuran (DFF) and 5-hydroxymethylfurancarboxylic acid (HMFCA), depending on the functional group of HMF that is oxidized first (Fig. 1, reactions 1 and 4, respectively). By additional oxidation, the above intermediates converge into 5-formylfurancarboxylic acid (FFCA), which is finally converted into FDCA (reactions 2, 5, and 3, respectively). In general, the chemical methods to obtain FDCA from HMF require high temperature, high pressure, metal catalysts, and organic solvents, which render the process polluting and expensive. For this reason, enzymatic conversion appears a suitable alternative, since enzymes are selective and act under mild conditions $[8,9]$.

Several enzymes are able to catalyze some of the above individual reactions in HMF conversion. On one hand, some oxidases act on the alcohol or aldehyde groups of these compounds with the only requirement of molecular oxygen as co-substrate. Among them, aryl-alcohol oxidase (AAO), a member of the glucose-methanol-choline oxidase/dehydrogenase (GMC) superfamily [10], typically oxidizes primary benzylic alcohols (i.e., those contiguous to an aromatic system) to the corresponding aldehydes [11], and hydrated aldehydes (gem-diols) to the corresponding acids [12] albeit the latter with lower efficiencies. In this way, the AAO from Pleurotus eryngii has been reported to selectively catalyze the oxidation of the hydroxyl group of HMF to produce DFF, and the subsequent oxidation of one of the aldehyde groups (hydrated as a gem-diol) in DFF to produce FFCA (reactions 1 and 2, respectively) [13]. However, its apparent inability to catalyze the full conversion into FDCA was simultaneously revealed. Moreover, galactose oxidase (GAO), a copper-radical enzyme oxidizing sugars [14], also transforms the hydroxyl group of primary benzylic alcohols into the corresponding aldehyde (as AAO does). Thus, GAO converts HMF into DFF and HMFCA into FFCA (reactions 1 and 5, respectively), but does not have any activity on DFF and FFCA [15]. Up to now, only one oxidase from Methylovorus sp., named hydroxymethylfurfural oxidase (HMFO) and also belonging to the GMC superfamily, has been reported to catalyze the total conversion of HMF into FDCA, through the DFF intermediate (reactions 1, 2, and 3), being the last oxidation (reaction 3 ) the limiting step for FDCA production [16, 17].

On the other hand, some heme-thiolate peroxidases/ peroxygenases can hydroxylate some of these compounds at the expenses of $\mathrm{H}_{2} \mathrm{O}_{2}$. Chloroperoxidase (CPO) from Leptoxyphium fumago is able to oxidize both the alcohol and aldehyde moieties of HMF giving rise to a mixture of HMFCA, DFF, FFCA, and FDCA (by a combination of reactions 1-5). By dosing the amount of $\mathrm{H}_{2} \mathrm{O}_{2}$, the mixture can be enriched in the final

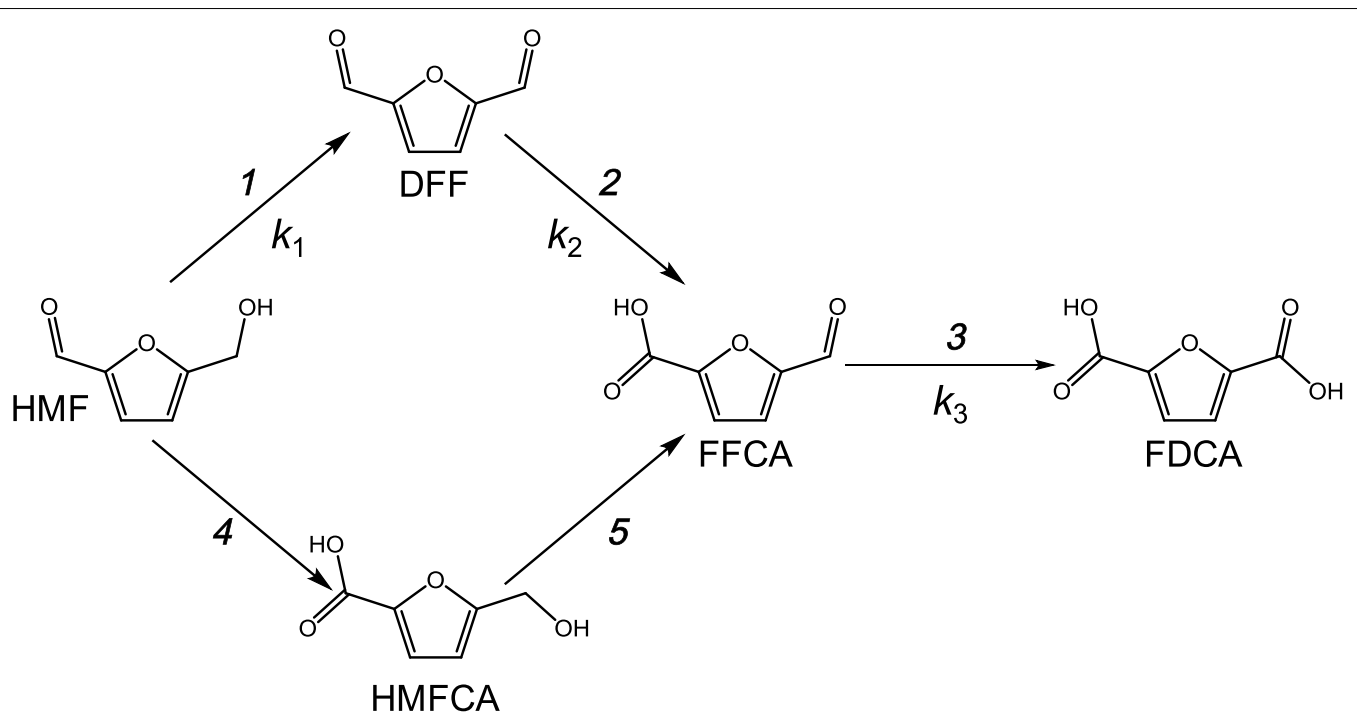

Fig. 1 Two convergent pathways to FDCA building block from renewable HMF: The conversion starts by oxidation of the HMF alcohol (reaction 1) or aldehyde (reaction 4) groups to DFF and HMFCA, respectively, and continues with oxidation of the latter intermediates to FFCA (reactions 2 and 5 , respectively) that is finally converted into FDCA (reaction 3) (the AAO rate constants, $k_{1}-k_{3}$, provided in Fig. 2 and Additional file 1: Table S1 are indicated) 
product. However, this HMF oxidation is not selective and different side-products are always produced [18]. Besides, the unspecific peroxygenase (UPO) from Agrocybe aegerita was found to oxidize HMF into FDCA via HMFCA and FFCA (reactions 4, 5, and 3, respectively) with variable yields [13] by a combination of hydroxylation and dehydration reactions [19]. Recently, the alternative oxidation of HMF to FFCA via DFF (reactions 1 and 2) by UPO has been also reported [15]. In any case, only low amounts of FDCA are obtained upon HMF oxidation by UPO alone.

Smart combinations of the above enzymes, including $\mathrm{AAO} / \mathrm{CPO}$ [18], AAO/UPO [13], GAO/UPO [20], and $\mathrm{AAO} / \mathrm{GAO} / \mathrm{UPO}$ [15], have been reported for the production of FDCA from HMF taking advantage of the fact that the by-product of oxidases, i.e., $\mathrm{H}_{2} \mathrm{O}_{2}$, is the co-substrate required by peroxidases/peroxygenases. However, cascades involving a combination of several enzymes have some disadvantages, such as the need to combine the different optimal operational conditions of each of them.

In the present work, we revise the lack of AAO activity on FFCA previously claimed [13], which was attributed to the low hydration degree of FFCA and/or to the deactivating effect that its carboxyl group causes on the hydride transfer reaction that characterizes AAO catalysis [21]. First, we demonstrate the ability of AAO to oxidize FFCA into FDCA. Second, we show that the control of the $\mathrm{H}_{2} \mathrm{O}_{2}$ levels during the reaction, by adding catalase, leads to $99 \%$ conversion of HMF into FDCA. Moreover, under such conditions, several AAO mutations at the active site are able to increase the rate of FFCA transformation into FDCA, consequently decreasing the reaction times and reaching higher conversion yields.

\section{Results}

\section{FFCA oxidation as the limiting step for FDCA production}

Incubation of either HMF or DFF $(1.5 \mathrm{mM})$ with AAO $(2.5 \mu \mathrm{M})$ resulted in accumulation of FFCA, without detection of FDCA after $72 \mathrm{~h}$ (Fig. 2a). The enzyme kept $\sim 80 \%$ of its activity during the first $48 \mathrm{~h}$, decreasing to $60 \%$ at the end of the 72 -h reaction. Conversion of HMF into DFF was the fastest oxidation step $\left(k_{1}=2.54 \mathrm{~h}^{-1}\right)$, while oxidation of DFF into FFCA was slower $\left(k_{2}=1.38 \mathrm{~h}^{-1}\right)$, although accumulation of DFF was only observed during the first $30 \mathrm{~min}$ (Fig. 3). At this time, a mixture of HMF (29\%), DFF (52\%), and FFCA (19\%) was found. HMF was totally consumed after $2 \mathrm{~h}$, whereas its total conversion into FFCA was completed in $4 \mathrm{~h}$. In contrast to previous studies [13], DFF was detected in the reaction mixture, which indicates that this compound leaves the active site before being rapidly converted into FFCA.
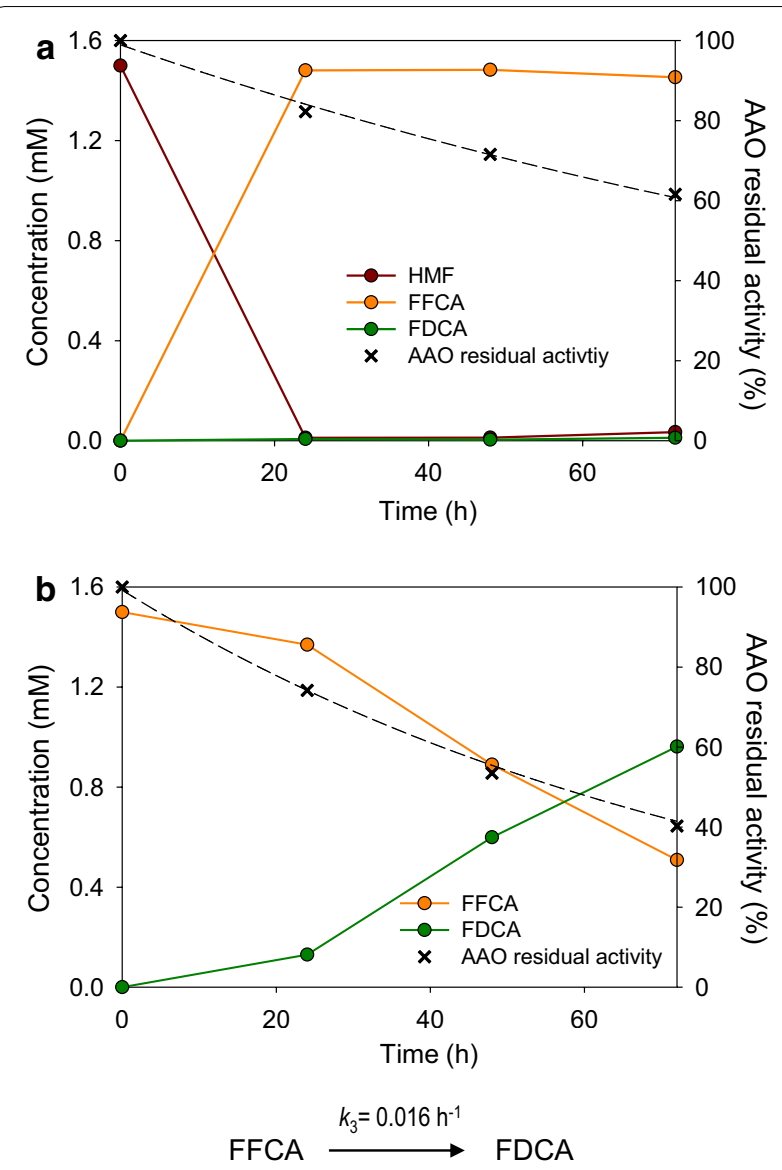

Fig. 2 Long-term oxidations of HMF (a) and FFCA (b) by AAO showing product molar percentages referred to initial substrate concentration (continuous lines) and enzyme residual activity (dashed lines). Reactions between 1.5 mM HMF or FFCA and $2.5 \mu \mathrm{M}$ AAO were performed in $50 \mathrm{mM}$ sodium phosphate, $\mathrm{pH} 6.0$, at $28^{\circ} \mathrm{C}$. Oxidation rate for FDCA production in $\mathbf{b}$, estimated by fitting data to equation $[\mathrm{FFCA}]=[\mathrm{FFCA}]_{0} e^{-k_{3} t}$, is indicated at the bottom

Surprisingly, production of FDCA was detected when FFCA was used as AAO substrate (Fig. 2b), but at a low rate $\left(k_{3}=0.016 \mathrm{~h}^{-1}\right)$ compared to HMF and DFF oxidation, resulting in $\sim 60 \%$ conversion after $72 \mathrm{~h}$. The residual activity of AAO after this period of time represented $40 \%$ of the initial activity.

In the light of these results, it can be concluded that AAO is able to oxidize FFCA into FDCA. However, this oxidation would be clearly the limiting step for the production of FDCA from HMF, given the much lower reaction rate.

\section{$\mathrm{H}_{\mathbf{2}} \mathrm{O}_{\mathbf{2}}$ has a negative effect on FFCA oxidation}

AAO is able to oxidize FFCA into FDCA, but this oxidation does not take place when FFCA originates from the previous oxidation of HMF and DFF. Moreover, addition 


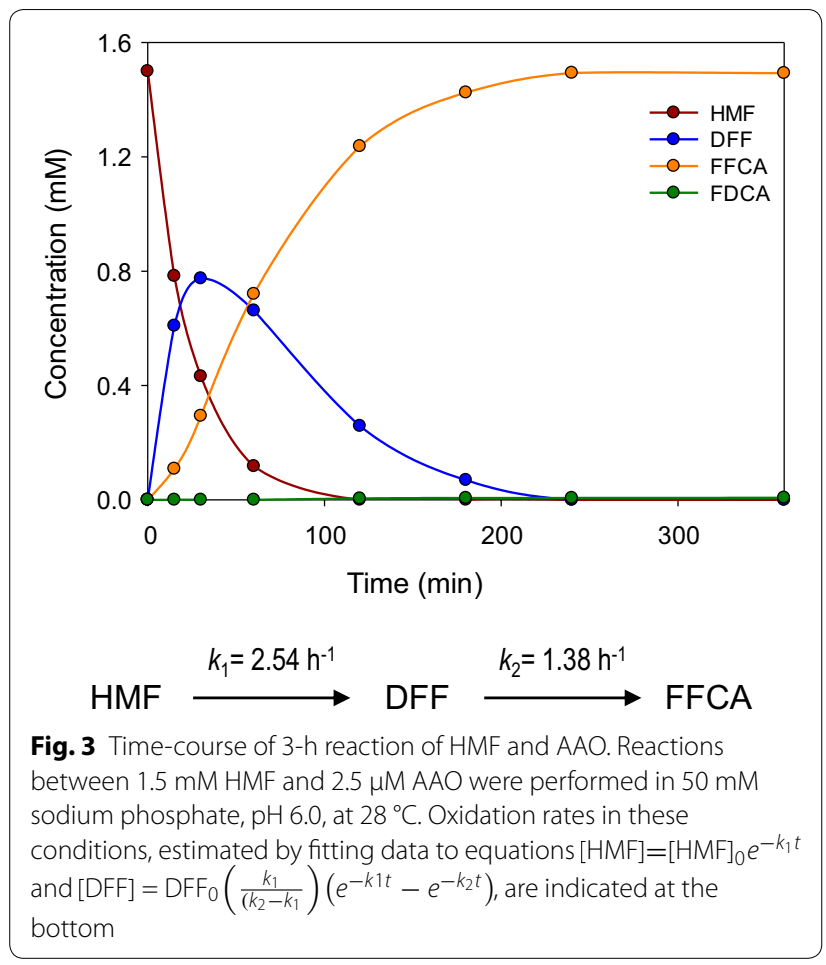

of new biocatalyst after $3 \mathrm{~h}$ of reaction (when all HMF was converted into FFCA) did not promote oxidation of the accumulated FFCA to FDCA (data not shown). Since the only difference between these two reaction setups is the presence of two equivalents of $\mathrm{H}_{2} \mathrm{O}_{2}$ (formed in the subsequent oxidations of HMF and DFF), we evaluated the effect that peroxide has on both the activity and the stability of AAO.

As shown in Fig. 4, the enzyme remained stable in the presence of increasing concentrations of $\mathrm{H}_{2} \mathrm{O}_{2}$ (up to $7.5 \mathrm{mM}$ ) maintaining at least $80 \%$ of its initial activity after $96 \mathrm{~h}$ of incubation at $25^{\circ} \mathrm{C}$. On the other hand, the effect of peroxide on the activity of AAO was assessed for the oxidation of its natural substrate, $p$-methoxybenzyl alcohol, and $p$-anisaldehyde [22]. The results, summarized in Table 1, indicate that the alcohol and aldehyde oxidation activities of AAO on these substrates are independent of the presence of $\mathrm{H}_{2} \mathrm{O}_{2}$.

The possible effect that increasing amounts of FFCA might exert on AAO activity was also evaluated. The results indicate that FFCA does not affect the kinetic parameters for AAO oxidation of $p$-methoxybenzyl alcohol either (Table 2).

Taking into consideration that the enzyme is stable against $\mathrm{H}_{2} \mathrm{O}_{2}$ and its activity (in the $p$-methoxybenzyl alcohol standard assay) is not inhibited by the products of the reaction $\left(\mathrm{H}_{2} \mathrm{O}_{2}\right.$ and FFCA), reactions on HMF, DFF, and FFCA were performed in the presence of increasing

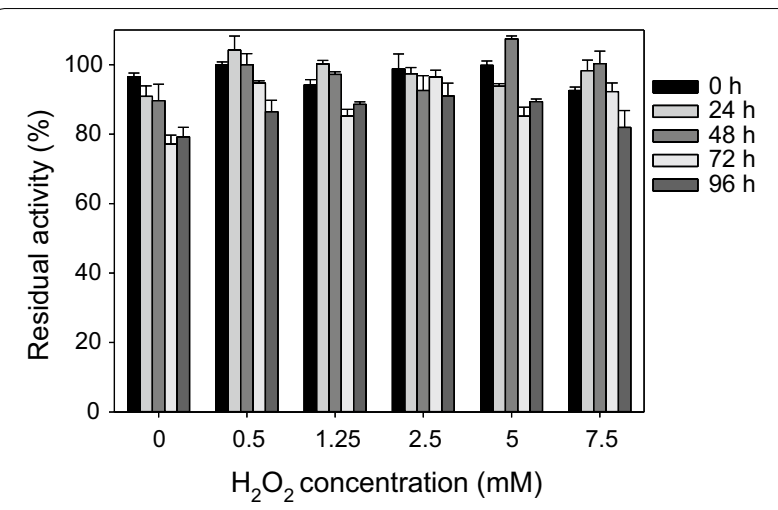

Fig. 4 Residual activity of $A A O$ after different times of incubation of the enzyme $(\sim 3 \mu \mathrm{M})$ with increasing amounts of $\mathrm{H}_{2} \mathrm{O}_{2}$ (from 0 to $7.5 \mathrm{mM}$ ) in $50 \mathrm{mM}$ sodium phosphate, $\mathrm{pH} 6.0$, at $25^{\circ} \mathrm{C}$

amounts of $\mathrm{H}_{2} \mathrm{O}_{2}(1.5-6 \mathrm{mM})$ to evaluate its effect. The results showed that the production of neither DFF nor FFCA was affected by peroxide (Fig. 5a, b). In all cases, the rates of product formation were similar $\left(k_{1} \sim 2.5-\right.$ $2.7 \mathrm{~h}^{-1}$ and $k_{2} \sim 1.1-1.4 \mathrm{~h}^{-1}$, respectively, Additional file 1: Table S1) and the enzyme kept its activity along the whole course of the reaction. However, FDCA production was abolished by $\mathrm{H}_{2} \mathrm{O}_{2}$ when using FFCA as substrate, even with the lowest amounts of peroxide assayed (Fig. 5c). Taking these results into account, lower $\mathrm{H}_{2} \mathrm{O}_{2}$ concentrations (0.0125-1.2 mM) were also evaluated for FFCA oxidation to FDCA (Additional file 1: Fig. S1). The results point out a strong inhibition of this reaction by $\mathrm{H}_{2} \mathrm{O}_{2}$ with an estimated half maximal inhibitory concentration $\left(\mathrm{IC}_{50}\right)$ of $\sim 158 \mu \mathrm{M}$. Altogether, these results indicate that only the oxidation of FFCA is somehow affected by the presence of $\mathrm{H}_{2} \mathrm{O}_{2}$ in the reaction mixture, at concentrations as low as $12.5 \mu \mathrm{M}$, and especially over $0.4 \mathrm{mM}$, under our experimental conditions.

\section{Complete HMF conversion by AAO in presence of catalase}

To overcome the negative effect that $\mathrm{H}_{2} \mathrm{O}_{2}$ has on the oxidation of FFCA by AAO, catalase was added to HMF, DFF, and FFCA reactions. Since the amount of AAO was decreased to $1.5 \mu \mathrm{M}$ in these experiments, the reactions in the presence and absence of catalase were followed for 12 days, with aliquot sampling every $24 \mathrm{~h}$, trying to achieve total conversion of the substrates. The oxidized products were analyzed by HPLC, and the $\mathrm{H}_{2} \mathrm{O}_{2}$ formed was spectrophotometrically quantified in the reactions without catalase using the HRP-coupled assay. The AAO residual activity was also evaluated using the standard assay.

No FDCA production was detected from HMF or DFF in the absence of catalase, and the enzymatic 
Table 1 Kinetic parameters for the oxidation of $p$-methoxybenzyl alcohol and $p$-anisaldehyde by AAO in the presence of different $\mathrm{H}_{2} \mathrm{O}_{2}$ concentrations

\begin{tabular}{|c|c|c|c|c|c|}
\hline \multicolumn{4}{|c|}{ p-Methoxybenzyl alcohol } & \multicolumn{2}{|c|}{ p-Anisaldehyde } \\
\hline$\left[\mathrm{H}_{2} \mathrm{O}_{2}\right](\mathrm{mM})$ & $k_{\text {cat }}\left(\mathrm{s}^{-1}\right)$ & $K_{\mathrm{m}}(\mu \mathrm{M})$ & $k_{\mathrm{cat}} / K_{\mathrm{m}}\left(\mathrm{s}^{-1} \mathrm{mM}^{-1}\right)$ & {$\left[\mathrm{H}_{2} \mathrm{O}_{2}\right](\mathrm{mM})$} & $k_{\text {cat }}\left(\min ^{-1}\right)$ \\
\hline 0 & $108 \pm 3$ & $31.8 \pm 3.2$ & $3390 \pm 360$ & 0 & $7.3 \pm 0.7$ \\
\hline 0.5 & $115 \pm 3$ & $44.3 \pm 3.5$ & $2600 \pm 220$ & 1.0 & $7.3 \pm 0.2$ \\
\hline 1.0 & $104 \pm 3$ & $33.5 \pm 3.4$ & $3100 \pm 330$ & 1.5 & $6.5 \pm 0.3$ \\
\hline 1.9 & $109 \pm 4$ & $35.6 \pm 4.3$ & $3060 \pm 390$ & 3.1 & $6.7 \pm 0.6$ \\
\hline 7.7 & $100 \pm 4$ & $33.7 \pm 4.5$ & $2970 \pm 420$ & 9.3 & $6.9 \pm 0.5$ \\
\hline 15.5 & $97 \pm 3$ & $31.0 \pm 2.6$ & $3120 \pm 280$ & 12.3 & $6.9 \pm 0.1$ \\
\hline
\end{tabular}

Activity was followed by measuring aldehyde formation (in $p$-methoxybenzyl alcohol oxidation) or acid formation (in $p$-anisaldehyde oxidation). Turnovers for aldehyde oxidation were calculated at saturating concentration of $p$-anisaldehyde $(\sim 5 \mathrm{mM})$ at $25^{\circ} \mathrm{C}$ in air-saturated $(0.256 \mathrm{mM} \mathrm{O}) 50 \mathrm{mM}$ sodium phosphate, $\mathrm{pH} 6.0$

Table 2 Kinetic parameters for the oxidation of $p$-methoxybenzyl alcohol by AAO in the presence of different FFCA concentrations

\begin{tabular}{llll}
\hline$[F F C A](\mathbf{m M})$ & $\boldsymbol{k}_{\mathbf{c a t}}\left(\mathbf{s}^{-\mathbf{1}}\right)$ & $\boldsymbol{K}_{\mathbf{m}}(\boldsymbol{\mu M})$ & $\boldsymbol{k}_{\text {cat }} / \boldsymbol{K}_{\mathbf{m}}\left(\mathbf{s}^{-\mathbf{1}} \mathbf{m M}^{-\mathbf{1}}\right)$ \\
\hline 0 & $84.5 \pm 2.1$ & $35.3 \pm 2.8$ & $2390 \pm 200$ \\
0.4 & $68.0 \pm 3.3$ & $33.0 \pm 5.0$ & $2120 \pm 350$ \\
0.8 & $78.9 \pm 1.7$ & $37.9 \pm 2.5$ & $2080 \pm 140$ \\
1.5 & $73.8 \pm 3.4$ & $37.0 \pm 5.1$ & $1990 \pm 290$ \\
3.0 & $66.9 \pm 2.3$ & $31.8 \pm 3.6$ & $2100 \pm 250$ \\
6.0 & $61.9 \pm 2.6$ & $27.6 \pm 2.6$ & $2250 \pm 220$ \\
\hline
\end{tabular}

Activity was followed by measuring the $\mathrm{H}_{2} \mathrm{O}_{2}$ released using AmplexRed ${ }^{\circledR}$ and $\mathrm{HRP}$ at $25^{\circ} \mathrm{C}$ in air-saturated $\left(0.256 \mathrm{mM} \mathrm{O}_{2}\right) 50 \mathrm{mM}$ sodium phosphate, $\mathrm{pH} 6.0$

activity decreased to $\sim 20 \%$ at the end of the treatment (Fig. 6a, b, closed circles). Addition of catalase leads to the production of FDCA attaining a 100\% yield after 12 days, although the final residual activity was below $10 \%$ (Fig. 6a, b, open circles). In the case of FFCA, the effect of catalase was negligible and a 100\% FDCA yield was achieved in both conditions, keeping the enzyme $10 \%$ of its initial activity (Fig. 6c).

Based on the experimental conversions obtained in the absence of catalase, the theoretical equivalents of $\mathrm{H}_{2} \mathrm{O}_{2}$ formed were calculated, and compared with the amount of $\mathrm{H}_{2} \mathrm{O}_{2}$ detected spectrophotometrically. In the HMF and DFF reactions, the peroxide detected almost equals the theoretical one: two equivalents for the two-step oxidation of HMF into FFCA (Fig. 7a) and one equivalent for the DFF direct oxidation into FFCA (Fig. 7b). Surprisingly, no peroxide was found in the reaction mixture when FFCA was used as substrate, while, according to the progress of the reaction, one equivalent of $\mathrm{H}_{2} \mathrm{O}_{2}$ should be detected at the end of the experiment (Fig. 7c).

Spontaneous oxidation of FFCA and other substrates was excluded, since they remained as the most abundant
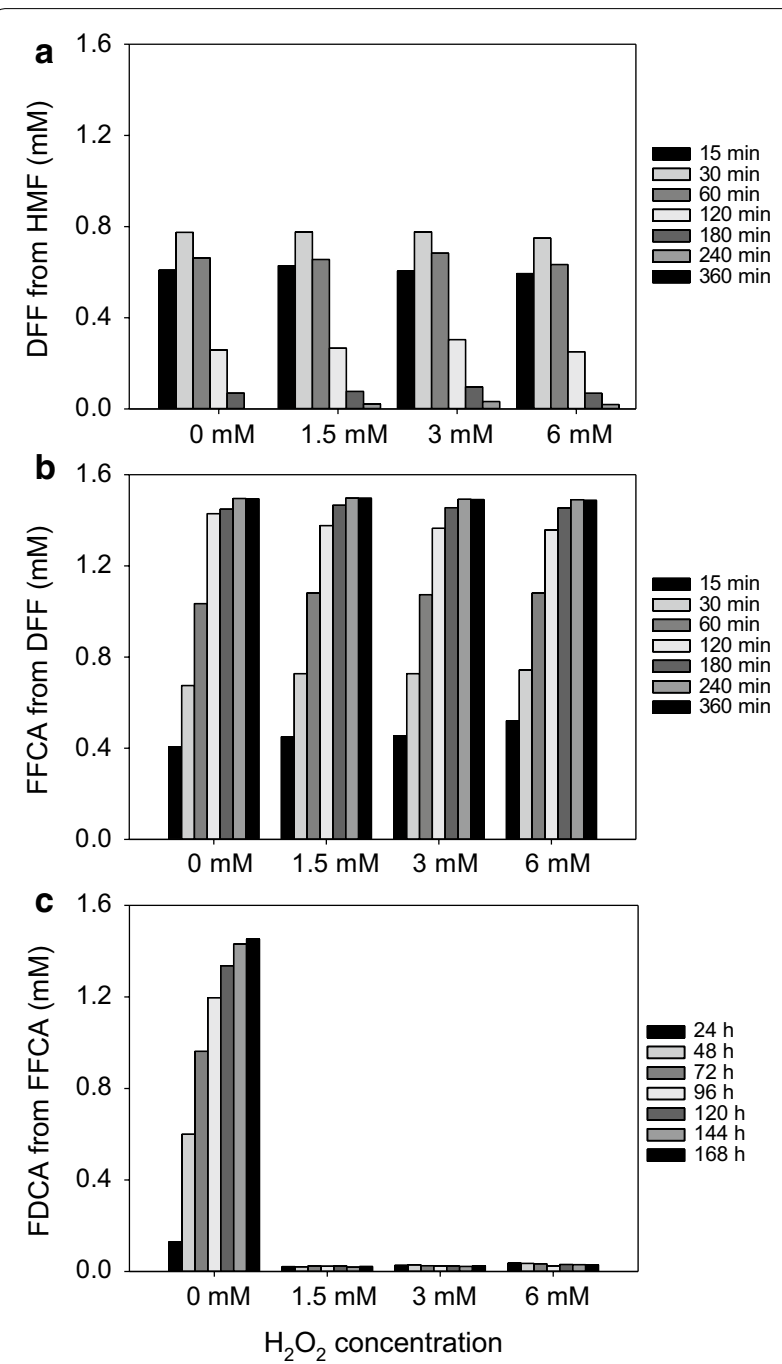

Fig. 5 Effect of $\mathrm{H}_{2} \mathrm{O}_{2}$ on the oxidation of $\operatorname{HMF}(\mathbf{a}), \operatorname{DFF}(\mathbf{b})$, and FFCA (c) by AAO. Reactions between $1.5 \mathrm{mM} \mathrm{HMF}$, DFF, or FFCA and $2.5 \mu \mathrm{M}$ AAO were performed in $50 \mathrm{mM}$ sodium phosphate, $\mathrm{pH} 6.0$, at $28^{\circ} \mathrm{C}$ in the presence of different amounts of $\mathrm{H}_{2} \mathrm{O}_{2}$ 

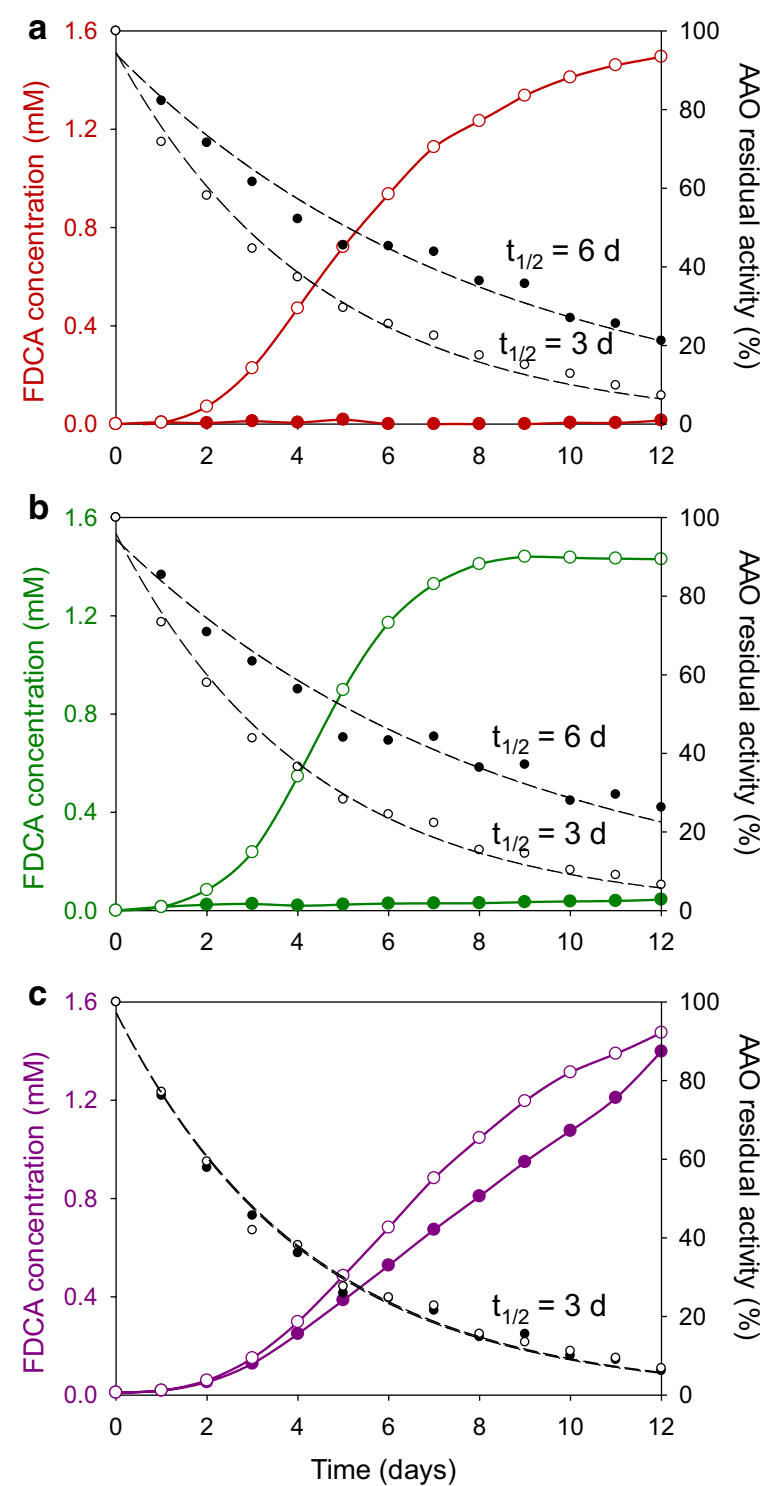

Fig. 6 FDCA production by AAO along time in the absence (closed circles) and presence of catalase (open circles) using HMF (a), DFF (b), and FFCA (c) as substrate. Dashed lines represent AAO residual activity along the time course of the reaction, enabling half-life $\left(t_{1 / 2}\right)$ calculation. Reactions between $1.5 \mathrm{mM}$ substrate and $1.5 \mu \mathrm{M}$ AAO (and catalase $2-5 \mathrm{U} / \mathrm{mL}$ ) were performed in $50 \mathrm{mM}$ sodium phosphate, $\mathrm{pH} 6.0$, at $28^{\circ} \mathrm{C}$

compounds after 12-day incubation in the absence of AAO ( $75-80 \%$ of the compounds detected in controls, Additional file 1: Fig. S2A-C). Since some oxidase activity (independent of $\mathrm{H}_{2} \mathrm{O}_{2}$ ) has been suggested for catalase acting on these compounds [15], controls were also incubated with this enzyme, but the results (similar to the first controls) indicate that catalase does not oxidize the substrates (Additional file 1: Fig. S2D-F).

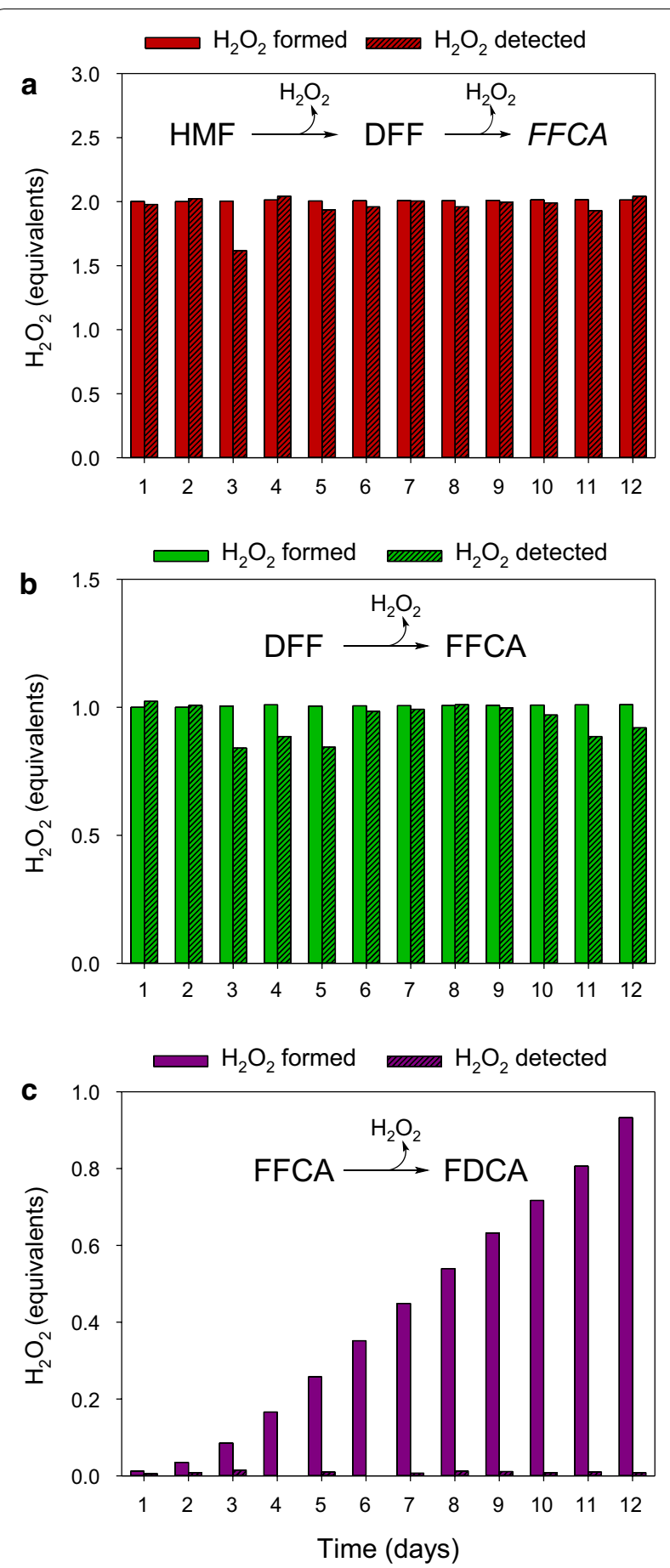

Fig. 7 Comparison of the $\mathrm{H}_{2} \mathrm{O}_{2}$ equivalents detected (with AmplexRed/HRP) and the theoretical equivalents formed (according to the experimental conversion rates and the expected oxidase-type activity on all the substrates) in the reactions of $\operatorname{HMF}(\mathbf{a}), \operatorname{DFF}(\mathbf{b})$, and FFCA (c) with AAO in absence of catalase. Reactions between $1.5 \mathrm{mM}$ substrate and $1.5 \mu \mathrm{M}$ AAO were performed in $50 \mathrm{mM}$ sodium phosphate, $\mathrm{pH} 6.0$, at $28^{\circ} \mathrm{C}$ 


\section{Analysis of HMF oxidation by AAO in the NMR tube}

Taking the previous results into account, we looked into the possible formation of a dead-end FFCA product, which might be unstable under the HPLC analysis conditions (with $10 \mathrm{mM} \mathrm{H}_{2} \mathrm{SO}_{4}$ as mobile phase). Therefore, we analyzed the oxidation of HMF by AAO in real time by ${ }^{1} \mathrm{H}$-nuclear magnetic resonance $\left({ }^{1} \mathrm{H}-\mathrm{NMR}\right)$ in the NMR tube in the absence (Fig. 8a) and presence (Fig. 8b) of catalase. The aim was to identify the potential deadend product in the HMF reactions. Under both conditions, a first spectrum of the substrate was recorded before addition of the enzyme (spectra 1 and $1^{\prime}$, Fig. 8). Then, both reactions were monitored according to the characteristic signals of each compound (see Additional file 1: Fig. S3 for NMR spectra of standard compounds).

Immediately after the addition of AAO (spectra 2 and 2 ', Fig. 8), a decrease in the HMF signals (at 4.5, 6.4, and $9.2 \mathrm{ppm}$ ), together with the appearance of DFF signals (at 5.9, 7.4 and $9.5 \mathrm{ppm}$ ), can be observed, consistent with the fast DFF formation from HMF (Fig. 3). As the DFF signals decrease, new distinctive signals appear that correspond to the subsequent formation of FFCA (at 6.9 and 9.4 ppm) under both conditions (spectra 3 and $3^{\prime}$, Fig. 8). In the absence of catalase, the evolution of the spectra leads to the disappearance of HMF signals (spectra 4-7, Fig. 8a) finally resulting in the spectrum of FFCA (spectrum 8 in Fig. 8a). However, when catalase was present, the spectrum of FFCA (5', Fig. 8b) evolved to the formation of FDCA with a single signal at $6.8 \mathrm{ppm}$ (spectra $6^{\prime}-8^{\prime}$, Fig. 8b). This signal was slightly displaced with respect to the standard, but addition of external FDCA allowed its unequivocal identification. Therefore, under these conditions, FDCA was the final compound of the reaction.

Quantification of the NMR signals leads to kinetic profiles similar to the ones obtained from the HPLC analyses (Fig. 6a, b), showing the total conversion of HMF into FFCA in the absence of catalase (Additional file 1: Fig. S4A) and the complete conversion of HMF into FDCA when catalase was present in the reaction mixture (Additional file 1: Fig. S4B). The NMR profiles also indicate that the mass balance is maintained throughout the reaction, ruling out the formation of undetected dead-end products.

\section{Improved FDCA production by AAO mutated variants}

The above results first confirm that AAO is able to catalyze the three oxidation steps in the conversion of HMF into FDCA. Second, they reveal that addition of catalase to eliminate the $\mathrm{H}_{2} \mathrm{O}_{2}$ produced during the reactions results in total HMF oxidation to FDCA. AAO has a buried active site in front of the re side of the isoalloxazine ring of FAD (Additional file 1: Fig. S5) [23]. Hence, several AAO variants, mutated in residues located at the active site or its access channel (Additional file 1: Fig. S6), were evaluated for the production of FDCA under the above conditions (Fig. 9). The best candidates were Y92L and F397Y with more than 70\% FDCA yield and I500M and $\mathrm{F} 501 \mathrm{H}$ with $80 \%$ and $97 \%$ FDCA yields, respectively, after 6 days. These variants showed higher catalytic efficiencies or higher turnover numbers for the transformation of HMF and/or DFF (Additional file 1: Table S2).

The above reaction conditions $(1.5 \mathrm{mM}$ of substrate and $1.5 \mu \mathrm{M}$ of enzyme) are far from being optimal for scaling up the HMF conversion. However, we increased the amount of FDCA obtained by using higher concentrations of HMF (15 mM), trying to attain saturating conditions. Under these conditions, the amount of FDCA produced increased around fivefold for the native enzyme and the F397Y and F501H variants, and up to tenfold for $1500 \mathrm{M} / \mathrm{F} 501 \mathrm{~W}$, reaching total turnover number (TTN) over 16,000 (Table 3).

\section{Discussion}

AAO from $P$. eryngii is a model GMC oxidoreductase, whose structural-functional relationships, catalytic mechanisms, and biotechnological interest have been largely investigated [11, 21, 23-25]. In contrast to the results obtained with the related GMC from Methylovorus sp. HMFO [16, 17], previous studies had suggested that the AAO from $P$. eryngii was unable to oxidize FFCA. As a consequence, a combination of AAO with $A$. aegerita UPO was used for the complete conversion of HMF into FDCA [13].

Here, we demonstrate that AAO is able to oxidize FFCA despite the fact that the conversion from HMF stops at the FFCA level. The main difference between the conversion of added FFCA and the conversion of the FFCA formed from HMF is the two equivalents of $\mathrm{H}_{2} \mathrm{O}_{2}$ present in the latter case. The results of $\mathrm{AAO}$ incubation with $\mathrm{H}_{2} \mathrm{O}_{2}$ showed that the enzyme is relatively stable against peroxide, but its reaction on FFCA is inhibited by all peroxide concentrations $(\geq 12.5 \mu \mathrm{M})$. Such inhibitory effect is confirmed by catalase addition to the AAO reactions with HMF (and DFF), which results in FDCA production. Therefore, the addition of catalase enables the complete oxidation of HMF to FDCA by P. eryngii AAO, as reported for other reactions catalyzed by GMC oxidases $[26,27]$. The presence of an unstable dead-end product not detected under the HPLC conditions was ruled out by monitoring the HMF reactions (with/without catalase) directly in the NMR tube (with DFF/FFCA as the sole products along the catalase-free reaction, and DFF/FFCA/FDCA when catalase was added to the reaction). 


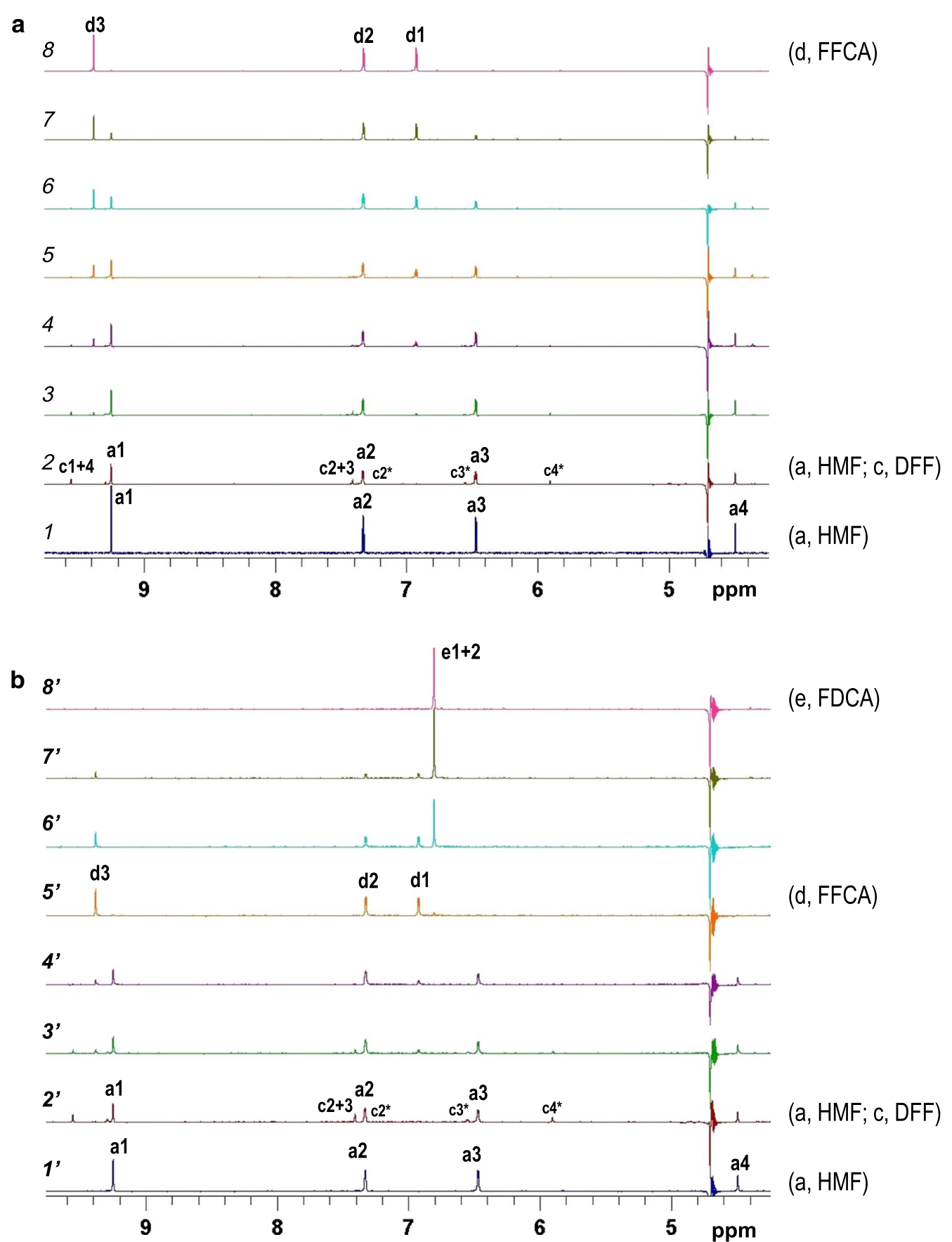

Fig. $8{ }^{1} \mathrm{H}$-NMR spectra along the reaction between HMF and AAO in the absence (a) and presence $(\mathbf{b})$ of catalase. Spectra 1 and $1^{\prime}$ were obtained before enzyme addition. Spectra 2 and $2^{\prime}$ were recorded immediately after enzyme addition. The rest of spectra $\left(3 / 3^{\prime}\right.$ to $\left.8 / 8^{\prime}\right)$ show the evolution of the reaction products during long-term incubation at $25^{\circ} \mathrm{C}$

Concerning the AAO oxidation of FFCA, kinetic studies, in combination with the chromatographic and NMR analyses of the reaction products, suggest that the reaction proceeds by a mechanism not described so far. In the case of HMF and DFF, the enzyme is first reduced by hydride abstraction from the substrate, and then reoxidized by $\mathrm{O}_{2}$ reduction releasing $\mathrm{H}_{2} \mathrm{O}_{2}$. However, during the direct oxidation of FFCA, full conversion to FDCA without $\mathrm{H}_{2} \mathrm{O}_{2}$ formation is observed. Similar monooxygenase activity has been reported in cholesterol 


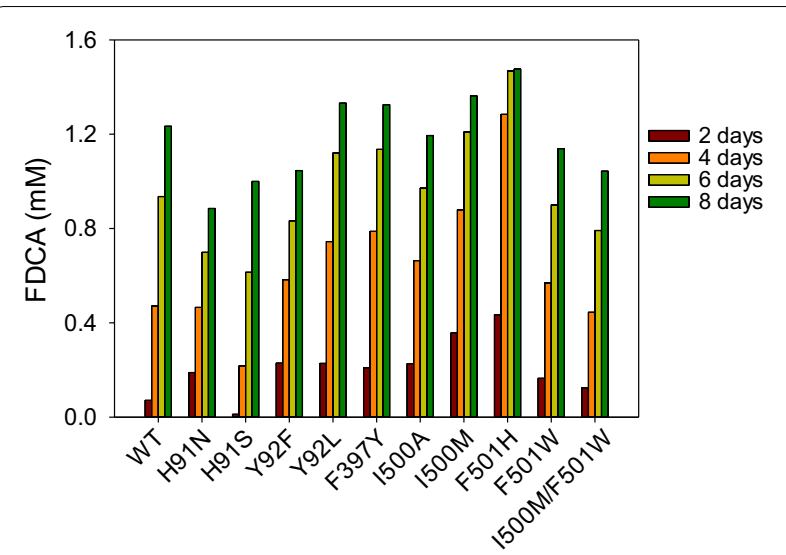

Fig. 9 FDCA production by AAO variants after different reaction times. Reactions between $1.5 \mathrm{mM}$ substrate and $1.5 \mu \mathrm{M}$ AAO in presence of $10 \mathrm{U} / \mathrm{mL}$ catalase were performed in $50 \mathrm{mM}$ sodium phosphate, $\mathrm{pH} 6.0$, at $28^{\circ} \mathrm{C}$

Table 3 Catalytic performance parameters for the production of FDCA from HMF by native AAO, and its F501H, F397Y, and $1500 \mathrm{M} / \mathrm{F} 501 \mathrm{~W}$ variants, in the presence of catalase (10$17 \mathrm{U} / \mathrm{mL}$ ) in $50 \mathrm{mM}$ sodium phosphate, $\mathrm{pH} 6.0$, at $28^{\circ} \mathrm{C}$, after 6 days of reaction

\begin{tabular}{llllr}
\hline AAO variant & [HMF] $(\mathbf{m M})$ & \% conversion & [FDCA] $\mathbf{~ m M ~}$ & TTN \\
\hline WT & 1.5 & 62.4 & 0.9 & 1980 \\
& 15 & 26.6 & 4.2 & 8440 \\
F501H & 1.5 & 97.9 & 1.6 & 3100 \\
& 15 & 43.0 & 6.8 & 13,600 \\
F397Y & 1.5 & 75.7 & 1.2 & 2400 \\
& 15 & 45.0 & 7.1 & 14,300 \\
I500M/F501W & 1.5 & 52.8 & 0.8 & 1670 \\
& 15 & 50.8 & 8.0 & 16,100 \\
\hline
\end{tabular}

oxidase, another member of the GMC superfamily, during hydroxylation of steroids [28]. FFCA conversion into FDCA by a comparable mechanism would be in agreement with the nearly negligible hydration degree of the former compound [13], a requisite for aldehyde oxidation by the AAO hydride abstraction mechanism [12].

Regarding the inhibition of the FFCA oxidation by the presence of $\mathrm{H}_{2} \mathrm{O}_{2}$, it is necessary to mention that a similar effect has been reported for glucose oxidase, another closely related GMC oxidase. Such inhibition is 100-fold faster during the enzyme oxidative half-reaction [29] and results from the strong competition of $\mathrm{H}_{2} \mathrm{O}_{2}$ with $\mathrm{O}_{2}$ [30]. In HMF conversion by AAO, the first two oxidation steps are comparatively fast $\left(k_{1}\right.$ and $k_{2}$ of 2.5 and $1.4 \mathrm{~h}^{-1}$, respectively) and no inhibitory effect of the $\mathrm{H}_{2} \mathrm{O}_{2}$ formed (or exogenously added) is observed. In contrast, the very slow FFCA conversion $\left(k_{3}\right.$ of $\left.0.016 \mathrm{~h}^{-1}\right)$ requires $\times 100$ reaction time (with the enzyme remaining under turnover conditions) and would result in the competitive inhibition of AAO by $\mathrm{H}_{2} \mathrm{O}_{2}$ (at concentrations as low as $12.5 \mu \mathrm{M}$, under the present conditions).

In addition to demonstrating that the AAO inability to fully oxidize HMF up to FDCA is due to the effect of the $\mathrm{H}_{2} \mathrm{O}_{2}$ formed in the first two oxidation steps, a procedure for the complete oxidation of HMF to FDCA by $P$. eryngii AAO in the presence of catalase, as reported for other reactions catalyzed by GMC oxidases [26, 27], is described here. Moreover, taking advantage of the beneficial effect of catalase on the HMF reactions, we were able to identify several directed variants in residues of the AAO active site. Those resulted in up to sixfold higher conversion to FDCA, in 2-d HMF reactions, than the native enzyme. This increase in FDCA production is justified by a higher relative activity on furfural aldehydes with regard to furfural alcohols, as shown by the $k_{\mathrm{cat}}^{\mathrm{DFF}} / k_{\mathrm{cat}}^{\mathrm{HMF}}$ ratio referred to the native enzyme (Additional file 1: Table S2) that increased up to 1.7-, 3.8-, and 10.7fold, respectively, for F397Y, I500M/F501 W, and F501H, three of the variants that yielded higher FDCA production (Table 3 and Fig. 9).

\section{Conclusions}

Here, we demonstrate how AAO can act on the aldehyde group of FFCA to produce FDCA. The lack of activity on this compound suggested in previous studies is caused by an inhibitory effect of the $\mathrm{H}_{2} \mathrm{O}_{2}$ formed during the previous oxidation steps when the starting substrate is HMF (or DFF). The use of catalase to remove the $\mathrm{H}_{2} \mathrm{O}_{2}$ produced throughout the reaction allowed achieving complete HMF oxidation, and the identification of several AAO variants with higher activity on HMF and DFF than the wild-type AAO. These variants, in turn, are able to increase the production of FDCA in shorter reaction times.

\section{Methods}

\section{Chemicals}

HMF was kindly provided by AVA Biochem. HMFCA, DFF, FDCA, $p$-methoxybenzyl alcohol, $p$-anisaldehyde (=p-methoxybenzaldehyde), catalase from bovine liver (2000-5000 U/mg), and $\mathrm{D}_{2} \mathrm{O}$ were purchased from Sigma-Aldrich (St. Louis, MO, USA). FFCA was purchased from TCI America (Portland, OR, USA). AmplexRed $^{\circledR}$ and horseradish peroxidase (HRP) were obtained from Invitrogen (Walthem, MA, USA). $\mathrm{H}_{2} \mathrm{O}_{2}$ was purchased from Merck (Darmstadt, Hessen, Germany). 


\section{Enzyme production and purification}

Native AAO from $P$. eryngii was obtained by expression of the mature AAO cDNA (GenBank AF064069) in $E$. coli followed by in vitro activation and purification as previously described [31].

Variants were produced by site-directed mutagenesis using synthetic primers (Additional file 1: Table S3) and the mutations were confirmed by gene sequencing. Variants were purified to electrophoretic homogeneity following the same protocol as for the native protein [31].

The concentrations of AAO and its variants were estimated in a Cary-100Bio spectrophotometer using their extinction coefficients (Additional file 1: Table S4), either taken from the literature, or calculated in the present work by heat denaturation [32] using $\varepsilon_{450}=11,300 \mathrm{M}^{-1}$ $\mathrm{cm}^{-1}$ for the free FAD [33].

\section{AAO stability against $\mathrm{H}_{2} \mathrm{O}_{2}$}

The AAO stability against $\mathrm{H}_{2} \mathrm{O}_{2}$ was estimated by preincubating the enzyme $(\sim 3 \mu \mathrm{M})$ in $50 \mathrm{mM}$ sodium phosphate, $\mathrm{pH}$ 6.0, with different $\mathrm{H}_{2} \mathrm{O}_{2}$ concentrations (from 0 to $7.5 \mathrm{mM}$ ). Residual activities were estimated by oxidation of saturating concentrations of $p$-methoxybenzyl alcohol in $50 \mathrm{mM}$ sodium phosphate, $\mathrm{pH}$ 6.0, at room temperature, immediately after mixing and after 24 -h, 48-h, 72-h, and 96-h incubation at $25{ }^{\circ} \mathrm{C}$. The highest activity after mixing was taken as $100 \%$ activity, and the percentages of residual activity at the different times and $\mathrm{H}_{2} \mathrm{O}_{2}$ concentrations were calculated according to this maximal value.

\section{Kinetic analyses}

Steady-state parameters for the AAO oxidation of $p$-methoxybenzyl alcohol were calculated by monitoring spectrophotometrically the initial rate of the oxidation of the alcohol to the corresponding aldehyde $\left(\Delta \varepsilon_{285}=16,950 \mathrm{M}^{-1} \mathrm{~cm}^{-1}\right)$ [34] at $25{ }^{\circ} \mathrm{C}$ in air-saturated $50 \mathrm{mM}$ sodium phosphate, $\mathrm{pH}$ 6.0. Different amounts of $\mathrm{H}_{2} \mathrm{O}_{2}$ were added to assess its inhibitory effect. To evaluate the possible inhibitory effect of FFCA, the kinetic parameters for the oxidation of $p$-methoxybenzyl alcohol were calculated by monitoring the production of $\mathrm{H}_{2} \mathrm{O}_{2}$ using an HRP-coupled assay with Amplex-Red ${ }^{\circledR}$ $\left(\Delta \varepsilon_{563}=52,000 \mathrm{M}^{-1} \mathrm{~cm}^{-1}\right)$ as the final substrate. In both cases, apparent kinetic parameters in atmospheric oxygen were determined by fitting the initial reaction rates at different alcohol concentrations to the MichaelisMenten equation:

$$
\frac{v}{e}=\frac{k_{\mathrm{cat}}[A]}{K_{m}+[A]}
$$

On the other hand, oxidation of $p$-anisaldehyde was measured spectrophotometrically by monitoring the initial formation rate of the corresponding acid using the calculated difference in the molar absorbance coefficients of the aldehyde and the acid $\left(\varepsilon_{\text {acid }}-\varepsilon_{\text {aldehyde }}\right.$, $\Delta \varepsilon_{247}=7139 \mathrm{M}^{-1} \mathrm{~cm}^{-1}$ ) at $25^{\circ} \mathrm{C}$ in air-saturated $50 \mathrm{mM}$ sodium phosphate, $\mathrm{pH}$ 6.0, in cuvettes of $1 \mathrm{~mm}$ of path length. To evaluate the inhibitory effect of $\mathrm{H}_{2} \mathrm{O}_{2}$, different amounts $(0-7.5 \mathrm{mM})$ were added to the reaction mixture with saturating concentration of aldehyde.

\section{Long-term oxidation of HMF, DFF, or FFCA}

FDCA production by AAO was assayed using $1.5-2.5 \mu \mathrm{M}$ enzyme with $1.5 \mathrm{mM}$ HMF, DFF, or FFCA in $50 \mathrm{mM}$ sodium phosphate, $\mathrm{pH} 6.0$, at $28{ }^{\circ} \mathrm{C}$, and $300 \mathrm{rpm}$ shaking. Samples were taken at different times and the reaction was stopped by adding $1 \mathrm{M} \mathrm{HCl} \mathrm{up} \mathrm{to} \mathrm{pH} 2-3$. The products of the reactions were analyzed by HPLC, using an ion-exchange Hi-Plex H column $(300 \times 7.7 \mathrm{~mm}, 8 \mu \mathrm{m}$ of particle size, Agilent Technologies). Compounds were eluted with $10 \mathrm{mM} \mathrm{H}_{2} \mathrm{SO}_{4}$ as mobile phase, at a flow rate of $0.8 \mathrm{~mL} / \mathrm{min}$, and $60{ }^{\circ} \mathrm{C}$. The retention times of FDCA, HMFCA, FFCA, HMF, and DFF were 14, 17, 19, 24, and 29 min, respectively (Additional file 1: Fig. S7A). Detection of the different compounds was done at $264 \mathrm{~nm}$ and their quantification was performed by the corresponding calibration curves (Additional file 1: Fig. S7B). As controls, solutions of the substrates were treated in the same way but in the absence of enzyme to monitor eventual spontaneous oxidation, and in the presence of catalase to check a possible oxidase activity.

AAO residual activity and the amount of $\mathrm{H}_{2} \mathrm{O}_{2}$ released along the reactions were measured by taking aliquots before addition of $\mathrm{HCl}$. Amplex-Red ${ }^{\circledR}$, in combination with HRP, was used to quantify the $\mathrm{H}_{2} \mathrm{O}_{2}$ released. In the presence of HRP, the Amplex- $\operatorname{Red}^{\circledR}$ reagent reacts with $\mathrm{H}_{2} \mathrm{O}_{2}$ in a 1:1 stoichiometry to produce resorufin, a colored compound with $\varepsilon_{563}=52,000 \mathrm{M}^{-1} \mathrm{~cm}^{-1}$. Quantification was performed using a calibration curve with known concentrations of $\mathrm{H}_{2} \mathrm{O}_{2}$. AAO residual activity was tested by measuring its activity against $p$-methoxybenzyl alcohol along the reaction, and these experimental values were fitted to Eq. 2 describing the enzymatic activity loss as a function of time. This allowed the estimation of the AAO half-life for each process (Eq. 3):

$$
\begin{aligned}
& \mathrm{AAO}_{\text {activity }}(\%)=\mathrm{AAO}_{\text {act } 0} e^{-\lambda t} \\
& t_{\frac{1}{2}}=\frac{\ln 2}{\lambda}
\end{aligned}
$$




\section{NMR assays}

Reactions between AAO and HMF, either in the absence or presence of catalase, were monitored by NMR spectroscopy. Reactions were performed in $5 \mathrm{~mm}$ NMR tubes in $50 \mathrm{mM}$ sodium phosphate, $\mathrm{pH} 6.0$, with $10 \%$ deuterated water $\left(\mathrm{D}_{2} \mathrm{O}\right)$ at $298 \mathrm{~K}$. The course of the reactions was monitored by acquiring ${ }^{1} \mathrm{H}-\mathrm{NMR}$ spectra at different reaction times until the complete conversion was achieved. NMR spectra were recorded by introducing the tube at the different reaction times in a Bruker (Billenica, MA, USA) Avance $500 \mathrm{MHz}$ instrument with the probe (triple resonance TXI) at $288 \mathrm{~K}$ to shift the ${ }^{1} \mathrm{H}$-NMR water signal for avoiding overlapping with the signal of the hydroxymethyl group of HMF. The spectra were referenced with water signal at $4.69 \mathrm{ppm}$. Spectra of the different furfurals were also acquired at $288 \mathrm{~K}$. The amount of each compound was calculated by integrating characteristic signals at: 4.5, 6.4, and 9.2 ppm for HMF; 5.9, 7.4, and 9.5 ppm for DFF, 6.3 and 9.4 ppm for FFCA, and $6.8 \mathrm{ppm}$ for FDCA (Additional file 1: Fig. S3).

\section{Supplementary information}

Supplementary information accompanies this paper at https://doi. org/10.1186/s13068-019-1555-Z.

Additional file 1: Table S1. It includes $\mathrm{H}_{2} \mathrm{O}_{2}$ effect on oxidation of furfurals. Table S2. Kinetic parameters of AAO variants. Table S3. Sequences of PCR primers. Table S4. Spectroscopic properties of AAO variants. Fig. S1. Effect of low $\mathrm{H}_{2} \mathrm{O}_{2}$ concentrations on FFCA oxidation. Fig. S2. Evolution of HMF, DFF and FFCA controls along time. Fig. S3. ${ }^{1} \mathrm{H}-\mathrm{NMR}$ spectra of furfural standards. Fig. S4. NMR time-course of HMF reactions. Fig. S5. Surface access to AAO active site. Fig. S6. Active site of native AAO and ten variants. Fig. S7. HPLC analyses of furfural standards.

\section{Abbreviations}

AAO: aryl-alcohol oxidase; CPO: chloroperoxidase; FDCA: 2,5-furandicarboxylic acid; FFCA: 5-formylfurancarboxylic acid; GAO: galactose oxidase; HMF: 5-hydroxymethylfurfural; HMFCA: 5-hydroxymethylfurancarboxylic acid; HRP: horseradish peroxidase; $k_{\text {cat }}$ : catalytic constant; $k_{\text {cat }} / K_{m}$ : catalytic efficiency; $K_{m}$ : Michaelis constant; PEF: poly(ethylene-furandicarboxylate); PET: poly(ethyleneterephthalate); TTN: total turnover number; UPO: unspecific peroxygenase.

\section{Acknowledgements}

We acknowledge support of the publication fee by the CSIC Open Access Publication Support Initiative through its Unit of Information Resources for Research (URICI). Marta Pérez-Boada (CIB, Madrid) is acknowledged for linguistic revision. AVA Biochem (Switzerland) is acknowledged for HMF supply.

\section{Authors' contributions}

AS performed the biocatalytic experiments and wrote the manuscript. EC and JC performed the NMR experiments. JC and MIS-R contributed to the enzymatic reactions. AS and ATM designed the experiments and revised the results and the manuscript content. All the authors revised the final version of the manuscript, and contributed to the discussion and conclusions obtained. All authors read and approved the final manuscript.

\section{Funding}

This work has been funded by the H2020 BBI-JU (https://www.bbi-europe.eu) project EnzOx2 (H2020-BBI-PPP-2015-2-720297; https://www.enzox2.eu) and the GENOBIOREF (BIO2017-86559-R) and CTQ2015-64597-C2-2-P projects of the Spanish Ministry of Economy, Industry and Competitiveness, co-financed by FEDER funds.

\section{Availability of data and materials}

The data sets supporting the conclusions of this article are included within the article (and its additional file).

\section{Ethics approval and consent to participate}

Not applicable.

\section{Consent for publication}

Not applicable.

\section{Competing interests}

The authors declare that they have no competing interests.

\section{Author details}

${ }^{1}$ Biotechnology for Lignocellulosic Biomass, Centro de Investigaciones Biológicas, CSIC, Ramiro de Maeztu 9, 28040 Madrid, Spain. ${ }^{2}$ NMR and Molecular Recognition, Centro de Investigaciones Biológicas, CSIC, Ramiro de Maeztu 9, 28040 Madrid, Spain.

Received: 19 June 2019 Accepted: 31 August 2019

Published online: 10 September 2019

References

1. Werpy T, Petersen G: Top value added chemicals from biomass. Vol. I: Results from screening for potential candidates from sugars and synthesis gas. Oak Ridge: DOE (http://www1.eere.energy.gov/biomass/pdfs/35523 .pdf), 2004

2. Bozell JJ, Petersen GR. Technology development for the production of biobased products from biorefinery carbohydrates-the US Department of Energy's "Top 10" revisited. Green Chem. 2010;12:539-54

3. Papageorgiou GZ, Tsanaktsis V, Bikiaris DN. Synthesis of poly(ethylene furandicarboxylate) polyester using monomers derived from renewable resources: thermal behavior comparison with PET and PEN. Phys Chem Chem Phys. 2014;16:7946-58.

4. Burgess SK, Leisen JE, Kraftschik BE, Mubarak CR, Kriegel RM, Koros WJ. Chain mobility, thermal, and mechanical properties of Poly(ethylene furanoate) compared to poly(ethylene terephthalate). Macromolecules. 2014;47:1383-91.

5. Rosatella AA, Simeonov SP, Frade RFM, Afonso CAM. 5-Hydroxymethylfurfural (HMF) as a building block platform: biological properties, synthesis and synthetic applications. Green Chem. 2011;13:754-93.

6. Hu L, He A, Liu X, Xia J, Xu J, Zhou S, Xu J. Biocatalytic transformation of 5-hydroxymethylfurfural into high-value derivatives: recent advances and future aspects. ACS Sustain Chem Eng. 2018;6:15915-35.

7. Kohli K, Prajapati R, Sharma KB. Bio-based chemicals from renewable biomass for integrated biorefineries. Energies. 2019;12:233.

8. Rajesh RO, Pandey A, Binod P. Bioprocesses for the production of 2,5-furandicarboxylic acid. In: Varjani S, Binod P, Kumar S, Khare SK, editors. Biosynthetic technology and environmental challenges. Chapter 8. Berlin: Springer; 2018.

9. Sheldon RA, Woodley JM. Role of biocatalysis in sustainable chemistry. Chem Rev. 2018:118:801-38.

10. Cavener DR. GMC oxidoreductases. A newly defined family of homologous proteins with diverse catalytic activities. J Mol Biol. 1992;223:811-4.

11. Hernández-Ortega A, Ferreira P, Martínez AT. Fungal aryl-alcohol oxidase: a peroxide-producing flavoenzyme involved in lignin degradation. Appl Microbiol Biotechnol. 2012;93:1395-410.

12. Ferreira $P$, Hernández-Ortega $A$, Herguedas B, Rencoret J, Gutiérrez A, Martínez MJ, Jiménez-Barbero J, Medina M, Martínez AT. Kinetic and chemical characterization of aldehyde oxidation by fungal aryl-alcohol oxidase. Biochem J. 2010;425:585-93.

13. Carro J, Ferreira P, Rodríguez L, Prieto A, Serrano A, Balcells B, Ardá A, Jiménez-Barbero J, Gutiérrez A, Ullrich R, Hofrichter M, Martínez AT. 5-Hydroxymethylfurfural conversion by fungal aryl-alcohol oxidase and unspecific peroxygenase. FEBS J. 2015:282:3218-29. 
14. Whittaker MM, Whittaker JW. Catalytic reaction profile for alcohol oxidation by galactose oxidase. Biochemistry. 2001;40:7140-8.

15. Karich A, Kleeberg BS, Ullrich R, Hofrichter M. Enzymatic preparation of 2,5-furandicarboxylic acid (FDCA)—A substitute of terephthalic acid-by the joined action of three fungal enzymes. Microorganisms. 2018;6:5.

16. Dijkman WP, Fraaije MW. Discovery and characterization of a 5-hydroxymethylfurfural oxidase from Methylovorus sp. strain MP688. Appl Environ Microbiol. 2014;80:1082-90.

17. Dijkman WP, Groothuis DE, Fraaije MW. Enzyme-catalyzed oxidation of 5-hydroxymethylfurfural to furan-2,5-dicarboxylic acid. Angew Chem. 2014;126:6633-6.

18. Hanke PD. Enzymatic oxidation of hydroxymethylfurfural. Patent (USA). $2012,8,183,020$ B2.

19. Hofrichter M, Kellner H, Herzog R, Karich A, Liers C, Scheibner K, Wambui V, Ullrich R. Fungal peroxygenases: a phylogenetically old superfamily of heme enzymes with promiscuity for oxygen transfer reactions. In: Nevalainen $\mathrm{H}$, editor. Grand challenges in fungal biotechnology. New York: Springer; 2019. p. 1-52.

20. Kalum L, Morant MD, Lund H, Jensen J, Lapainaite I, Soerensen NH, Pedersen S, Østergaard L, Xu F. Enzymatic oxidation of 5-hydroxymethylfurfural and derivatives thereof. Patent (International). 2014, WO2014-015256A2.

21. Hernández-Ortega A, Ferreira P, Merino P, Medina M, Guallar V, Martínez AT. Stereoselective hydride transfer by aryl-alcohol oxidase, a member of the GMC superfamily. ChemBioChem. 2012;13:427-35.

22. Gutiérrez A, Caramelo L, Prieto A, Martínez MJ, Martínez AT. Anisaldehyde production and aryl-alcohol oxidase and dehydrogenase activities in ligninolytic fungi from the genus Pleurotus. Appl Environ Microbiol. 1994;60:1783-8.

23. Fernández IS, Ruiz-Dueñas FJ, Santillana E, Ferreira P, Martínez MJ, Martínez AT, Romero A. Novel structural features in the GMC family of oxidoreductases revealed by the crystal structure of fungal aryl-alcohol oxidase. Acta Crystallogr D Biol Crystallogr. 2009;65:1196-205.

24. Carro J, Fernández-Fueyo E, Fernández-Alonso MC, Cañada FJ, Ullrich R, Hofrichter M, Alcalde M, Ferreira P, Martínez AT. Self-sustained enzymatic cascade for the production of 2,5-furandicarboxylic acid from 5-methoxymethylfurfural. Biotechnol Biofuels. 2018;11:86
25. Serrano A, Sancho F, Viña-Gonzalez J, Carro J, Alcalde M, Guallar V, Martínez AT. Switching the substrate preference of fungal aryl-alcohol oxidase: towards stereoselective oxidation of secondary benzyl alcohols. Catal Sci Technol. 2019;9:833-41.

26. Röcker J, Schmitt M, Pasch L, Ebert K, Grossmann M. The use of glucose oxidase and catalase for the enzymatic reduction of the potential ethanol content in wine. Food Chem. 2016;210:660-70.

27. Wong CM, Wong KH, Chen XD. Glucose oxidase: natural occurrence, function, properties and industrial applications. Appl Microbiol Biotechnol. 2008;78:927-38.

28. Molnár I, Hayashi N, Choi KP, Yamamoto H, Yamashita M, Murooka Y. Bacterial cholesterol oxidases are able to act as flavoprotein-linked ketosteroid monooxygenases that catalyse the hydroxylation of cholesterol to 4-cholesten-6-ol-3-one. Mol Microbiol. 1993;7:419-28.

29. Kleppe K. The effect of hydrogen peroxide on glucose oxidase from Aspergillus niger. Biochemistry. 1966;5:139-43.

30. Bao J, Furumoto K, Yoshimoto M, Fukunaga K, Nakao K. Competitive inhibition by hydrogen peroxide produced in glucose oxidation catalyzed by glucose oxidase. Biochem Eng J. 2003;13:69-72.

31. Ruiz-Dueñas FJ, Ferreira P, Martínez MJ, Martínez AT. In vitro activation, purification, and characterization of Escherichia coli expressed arylalcohol oxidase, a unique $\mathrm{H}_{2} \mathrm{O}_{2}$-producing enzyme. Protein Express Purif. 2006:45:191-9.

32. Aliverti A, Curti B, Vanoni MA. Identifying and quantitating FAD and FMN in simple and in iron-sulfur-containing flavoproteins. Methods Mol Biol. 1999;131:9-23.

33. Dawson RMC, Elliot DC, Elliot WH, Jones KM. Data for biochemical research. Oxford: Oxford Science Publications; 1986.

34. Ferreira P, Medina M, Guillén F, Martínez MJ, van Berkel WJH, Martínez AT. Spectral and catalytic properties of aryl-alcohol oxidase, a fungal flavoenzyme acting on polyunsaturated alcohols. Biochem J. 2005;389:731-8.

\section{Publisher's Note}

Springer Nature remains neutral with regard to jurisdictional claims in published maps and institutional affiliations.
Ready to submit your research? Choose BMC and benefit from:

- fast, convenient online submission

- thorough peer review by experienced researchers in your field

- rapid publication on acceptance

- support for research data, including large and complex data types

- gold Open Access which fosters wider collaboration and increased citations

- maximum visibility for your research: over $100 \mathrm{M}$ website views per year

At BMC, research is always in progress.

Learn more biomedcentral.com/submissions 